\title{
THE DEVELOPMENT OF ACCOUNTING LEARNING MEDIA USING LECTORA INSPIRE IN FINANCIAL STATEMENT TOPIC OF GRADE $X$ AT SMK NEGERI 1 MALANG
}

\author{
Nur Laili Saadah \\ Sriyani Mentari \\ Dodik Juliardi \\ Universitas Negeri Malang \\ nurlaili_akuntansi11@yahoo.co.id
}

\begin{abstract}
The aim of developing instructional media by using lectora inspire is to produce interactive instructional media and the effectiveness on the topic of financial statement of service and trading company tenth grade at SMK Negeri 1 Malang. The development of instructional media which refers to the steps of research and development by Borg \& Gall (1983) modified with Sadiman (2010) which are: 1) research and information collecting, 2) planning, 3) develop preliminary form of product, 4) production media, 5) expert validation, 6) revision of the product, 7) field trials, 8) revision of the results of field trials of products, 9) final product. The technique of data analysis in this research is using qualitative descriptive analysis and assumption test by using T-test independent sample. The method of development used is by experimenting the product. The final product of this study has overtaken the expert validation which result $80,46 \%$ valid in terms of materials given, $89,28 \%$ valid in terms of media, and $96,30 \%$ valid based on the result of the field trials, so that it was averaged $88,68 \%$ valid from the validation results. The result of T-Test independent sample acquired a significant result $0,015<0,05$ so that can be concluded that there was a significant distinction on the improvement of students' learning outcomes in the experimental and control class.
\end{abstract}

Keywords: developing instructional media, lectora inspire, financial statement.

Abstrak: Tujuan pengembangan media pembelajaran menggunakan lectora inspire adalah untuk menghasilkan produk media pembelajaran interaktif pada pokok bahasan laporan keuangan perusahaan jasa dan dagang kelas X di SMK Negeri 1 Malang dan untuk mengetahui keefektifan media pembelajaran terhadap hasil belajar siswa. Pengembangan media ini menggunakan metode pengembangan Borg and Gall (1983) yang dimodifikasi dengan Sadiman (2010) yang terdiri dari langkah (1) penelitian dan pengumpulan data, (2) perencanaan (planning), (3) pengembangan draft produk, (4) produksi media, (5) validasi ahli, (6) revisi produk, (7) uji coba lapangan, (8) revisi produk hasil uji coba lapangan, dan (9) produk akhir. Teknik analisis data menggunakan teknik analisis deskriptif kualitatif dan uji asumsi menggunakan Uji-T sampel independen. Metode penelitian pengembangan yang digunakan dengan mengeksperimenkan produk. Media pembelajaran yang dihasilkan secara keseluruhan telah melalui tahap validasi ahli sebagai berikut: validasi ahli materi sebesar $80,46 \%$, validasi ahli media sebesar $89,28 \%$, dan validasi uji coba lapangan sebesar $96,30 \%$ sehingga diperoleh rata-rata keseluruhan sebesar 88,68\%. Kemudian dari hasil analisis Uji-T sampel independen diperoleh nilai signifikansi sebesar $0,015<0,05$ sehingga dapat disimpulkan bahwa terdapat perbedaan peningkatan hasil belajar kelas eksperimen dan kelas kontrol.

Kata Kunci: pengembangan media pembelajaran, lectora inspire, laporan keuangan. 
Perkembangan ilmu pengetahuan dan teknologi informasi telah menggeser paradigma pembelajaran konvensional menuju pembelajaran yang berbasis teknologi (education based technology). Sejalan dengan perkembangan ilmu pengetahuan dan teknologi, penggunaan media dalam pembelajaran berbasis teknologi informasi dan komunikasi (Information and Communication Technologies, ICT) merupakan kebutuhan dalam rangka mencapai tujuan pembelajaran.

Program pembelajaran interaktif berbasis komputer memiliki nilai lebih dibandingkan dengan bahan pembelajaran tercetak biasa. Pembelajaran interaktif mampu mengaktifkan siswa untuk belajar dengan motivasi yang tinggi karena ketertarikannya pada sistem multimedia yang mampu menyuguhkan tampilan teks, gambar, video, sound, dan animasi. Sedangkan pembelajaran tercetak biasa cenderung membuat siswa bosan dalam belajar dikarenakan tebalnya buku cetak dan kurang menariknya buku tersebut.

Media pembelajaran adalah sebuah alat yang berfungsi untuk menyampaikan pesan pembelajaran. Pembelajaran adalah sebuah proses antara pembelajar, pengajar dan bahan ajar. Komunikasi tidak akan berjalan tanpa adanya bantuan sarana penyampai pesan atau media. Pemanfaatan media pembelajaran yang optimal dapat membantu efektivitas kegiatan pembelajaran. Supaya media pembelajaran dapat dimanfaatkan secara optimal perlu adanya pemilihan media pembelajaran yang tepat sesuai kebutuhan dan menarik bagi siswa. Hamalik (1986) dalam Arsyad (2013:19) mengemukakan bahwa pemakaian media pembelajaran dalam proses belajar mengajar akan dapat membangkitkan keinginan dan minat yang baru, membangkitkan motivasi, dan rangsangan kegiatan belajar, dan bahkan membawa pengaruhpengaruh psikologis terhadap siswa. Selain itu, penggunaan media pembelajaran pada tahap orientasi pembelajaran akan sangat membantu keefektifan proses pembelajaran dan penyampaian pesan dan isi pelajaran pada saat kegiatan pembelajaran berlangsung.

Penelitian ini dilaksanakan di SMK Negeri 1 Malang. Berdasarkan hasil observasi dan wawancara dengan guru akuntansi dan siswa akuntansi kelas X ditemukan bahwa diperlukan sebuah media pembelajaran akuntansi berbasis komputer untuk mengatasi kesulitan siswa dalam mempelajari materi laporan keuangan perusahaan jasa dan laporan keuangan perusahaan dagang untuk meningkatkan motivasi dan hasil belajar siswa. Media pembelajaran interaktif yang dihasilkan melalui program Lectora Inspire dapat digunakan siswa untuk belajar secara aktif untuk membangun pengetahuannya sendiri. Menurut teori belajar konstruktivistik yang diungkapkan oleh Budiningsih (2004:59) bahwa dalam belajar konstruktivistik peran guru atau pendidik adalah membantu agar proses pengkonstruksian 
pengetahuan oleh siswa berjalan lancar. Guru tidak mentransfer pengetahuan yang telah dimilikinya, melainkan membantu siswa untuk membentuk pengetahuannya sendiri. Guru dituntut untuk lebih memahami jalan pikiran atau cara pandang siswa dalam belajar. Guru tidak dapat mengklaim bahwa satu-satunya cara yang tepat adalah yang sama dan sesuai.

Tujuan penelitian dan pengembangan adalah (1) menghasilkan produk berupa media pembelajaran akuntansi menggunakan Lectora Inspire sebagai salah satu alternatif media pembelajaran inovatif untuk guru dan siswa kelas X Akuntansi di SMKN 1 Malang, (2) mengetahui efektivitas penggunaan media pembelajaran akuntansi menggunakan Lectora Inspire untuk siswa kelas X Akuntansi di SMKN 1 Malang.

\section{METODE}

Metode penelitian pengembangan yang digunakan peneliti untuk mengembangkan media pembelajaran akuntansi menggunakan lectora inspire adalah model penelitian pengembangan yang mengacu pada Borg and Gall (1983) yang dimodifikasi dengan Sadiman (2010) yang terdiri dari 9 langkah yaitu 1) penelitian dan pengumpulan data, 2) perencanaan, 3) pengembangan draft produk 4) produksi media, 5) validasi ahli, 6) revisi produk, 7) uji coba lapangan, 8) revisi produk hasil uji coba lapangan, dan 9) produk akhir.

Subjek uji coba dalam penelitian ini adalah siswa kelas X Akuntansi 1 SMK Negeri 1 Malang yang berjumlah 34 siswa. Sebelum dilakukan kegiatan uji coba lapangan terlebih dahulu dilakukan validasi terhadap media pembelajaran yang dikembangkan. Validator ahli media merupakan dosen jurusan Teknologi Pendidikan FIP UM dan validator ahli materi merupakan guru akuntansi SMK Negeri 1 Malang.

Teknik analisis data yang digunakan adalah deskriptif kualitatif yang menghasilkan data kuantitatif dan kualitatif. Data kuantitatif berupa skor yang diperoleh saat dilakukan penilaian terhadap media pembelajaran akuntansi oleh validator ahli media dan validator ahli materi serta uji coba pengguna siswa. Sedangkan data kualitatif berupa kritik dan saran serta pendapat secara umum mengenai media pembelajaran dari angket (kuesioner). Berikut ini merupakan skala yang dijadikan alat ukur dalam menilai kevalidan media pembelajaran menggunakan angket.

Skor 4: Sangat setuju/sangat tepat/sangat sesuai

Skor 3: Setuju/tepat/sesuai

Skor 2: Kurang setuju/kurang tepat/kurang sesuai

Skor 1: tidak setuju/tidak tepat/tidak sesuai 
Data yang diperoleh dari angket (kuesioner) tersebut kemudian dianalisis dengan rumus sebagai berikut:

$$
P=\frac{\sum X}{\sum X_{i}} \times 100 \%
$$

(Sumber: Sudjana, 2011:126)

Keterangan:

$\mathrm{P}=$ Persentase hasil subjek uji coba

$\mathrm{X}=$ Jumlah jawaban skor oleh subjek uji coba

$\mathrm{Xi}=$ Jumlah jawaban maksimal dalam aspek penilaian oleh subjek uji coba

Selanjutnya hasil akhir validasi yang telah dihitung menggunakan rumus tersebut diperoleh kriteria sebagai berikut.

Tabel 1. Persentase Evaluasi Subjek Uji Coba

\begin{tabular}{ll}
\hline \multicolumn{1}{c}{ Persentase Pencapaian } & \multicolumn{1}{c}{ Interpretasi } \\
\hline $80 \%-100 \%$ & Valid/Digunakan \\
\hline $60 \%-79 \%$ & Cukup Valid/Digunakan \\
\hline $50 \%-59 \%$ & Kurang Valid/Diganti \\
\hline$<50 \%$ & Tidak Valid/Diganti \\
\hline
\end{tabular}

Sumber: Adaptasi Sudjana (2011)

Pada tahap uji coba lapangan menggunakan metode eksperimen untuk menguji keampuhan produk yang telah dikembangkan. Berikut ini merupakan tabel rancangan desain uji coba produk menggunakan pretest-posttest control group design.

Tabel 2. Desain Uji Coba Produk Menggunakan Pretest-Posttest Control Group Design.

\begin{tabular}{rccc}
\hline Kelompok & Pretest & Perlakuan & Posttest \\
\hline Eksperimen 1 & $\mathrm{O}_{1}$ & $\mathrm{X}_{1}$ & $\mathrm{O}_{2}$ \\
Eksperimen 2 & $\mathrm{O}_{3}$ & Tanpa perlakuan & $\mathrm{O}_{4}$ \\
\hline
\end{tabular}

(Adaptasi Sukmadinata, 2013:207)

Keterangan:

$\mathrm{O}_{1}$ : pretest kelompok eksperimen

$\mathrm{O}_{2}$ : posttest kelompok eksperimen

$\mathrm{X}_{1}$ : pemberian perlakuan menggunakan media pembelajaran Lectora Inspire

$\mathrm{O}_{3}$ : pretest kelompok kontrol

$\mathrm{O}_{4}$ : posttest kelompok kontrol

Teknik analisis data yang digunakan untuk mengolah data hasil eksperimen adalah dengan melakukan uji normalitas, uji homogenitas, dan uji-t sampel independen. Dari hasil uji-t sampel independent maka dapat diketahui apakah terdapat perbedaan peningkatan hasil belajar antara kelas eksperimen dan kelas kontrol. 


\section{HASIL DAN PEMBAHASAN}

\section{Hasil}

Pada tahap ini diperoleh media pembelajaran interaktif tingkat operator yang telah diuji kevalidan dan kelayakannya oleh ahli media, ahli materi, dan pengguna siswa. Berikut ini disajikan tampilan media pembelajaran akuntansi menggunakan lectora inspire hasil pengembangan peneliti.

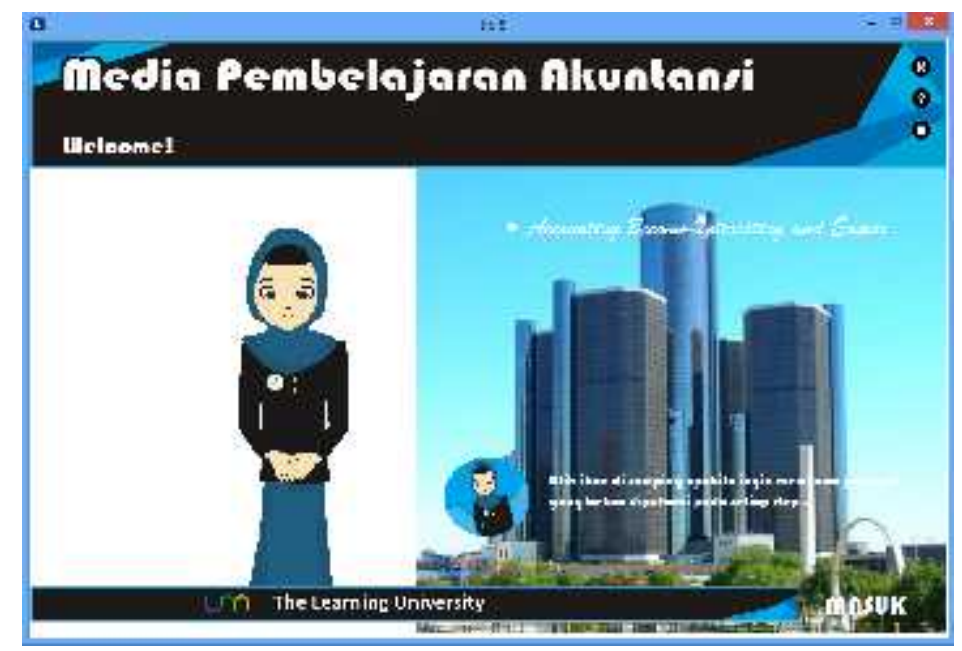

Gambar 1. Tampilan Halaman Awal (Home Page) pada Media

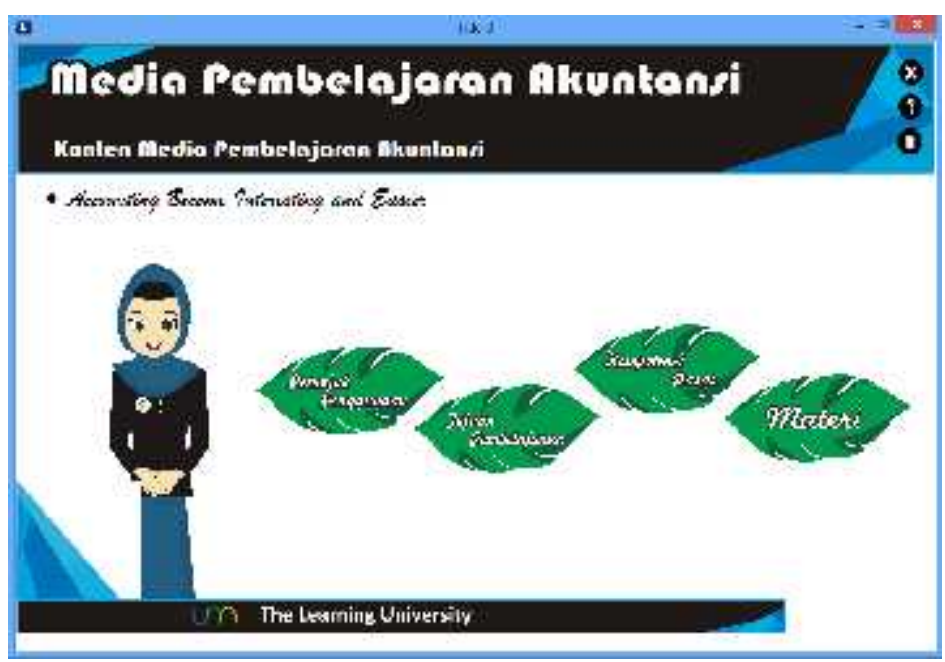

Gambar 2. Tampilan Halaman Awal pada Menu Media 


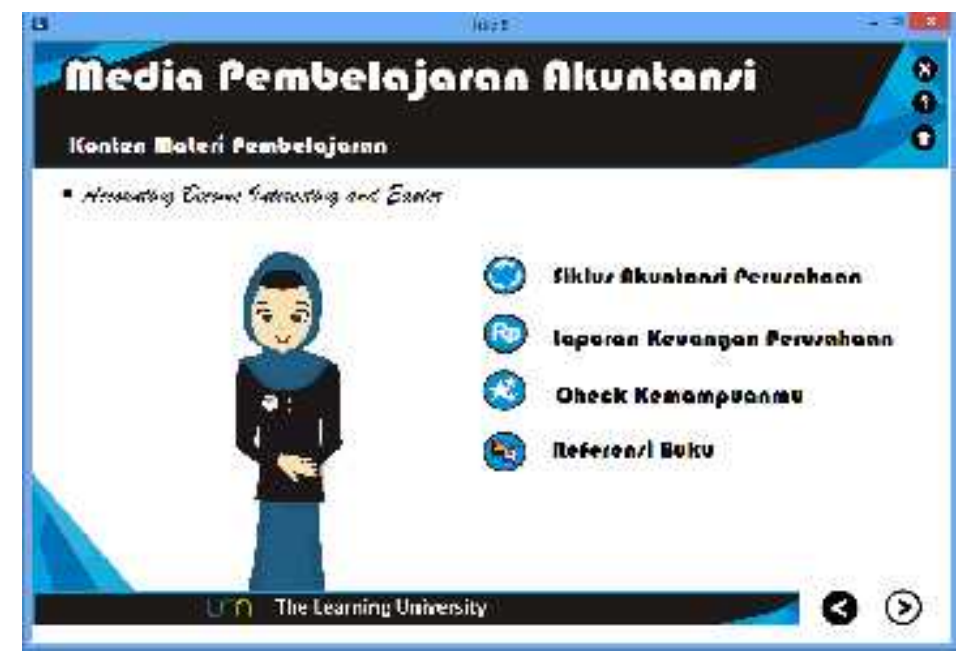

Gambar 3. Tampilan Halaman Materi pada Menu Media

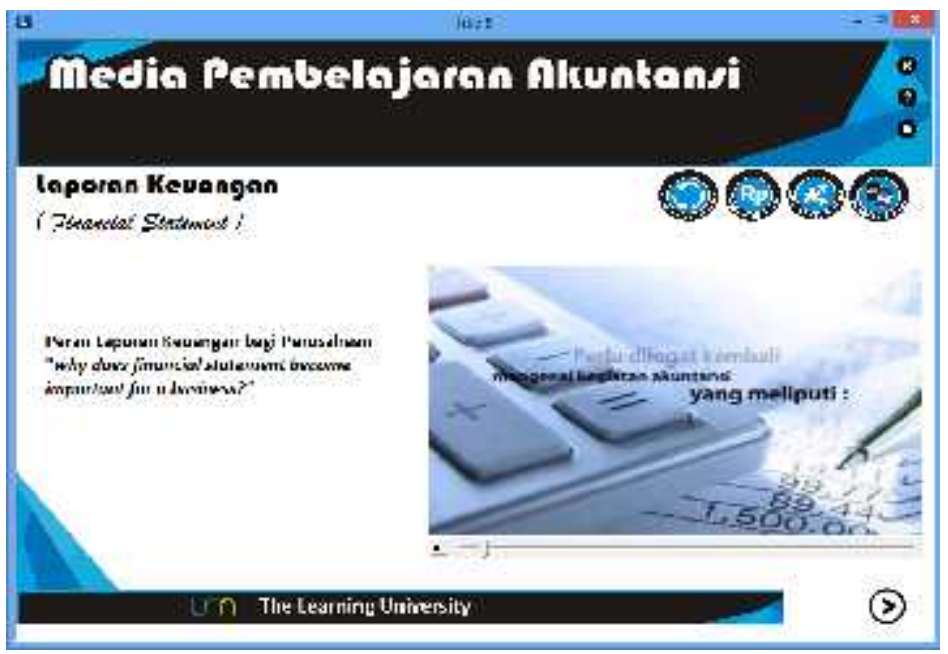

\section{Gambar 4. Tampilan Menu Materi Peran Laporan Keuangan}

Data hasil validasi ahli media diperoleh dari seorang dosen Teknologi Pendidikan Universitas Negeri Malang dan data hasil validasi ahli materi diperoleh dari seorang guru Akuntansi SMK Negeri 1 Malang. Data yang diperoleh dari hasil hasil validasi ahli media dan ahli materi merupakan data kuantitatif dan data kualitatif (deskriptif), data kualitatif berupa kritik dan saran dari ahli media dan ahli materi. Berikut merupakan kritik dan saran yang diberikan oleh ahli media.

\section{Tabel 3. Kritik dan Saran dari Ahli Media}

\begin{tabular}{cl}
\hline No. & \multicolumn{1}{c}{ Kritik dan Saran } \\
\hline 1 & Cantumkan profil pengembang \\
2 & Audio (kualitas dan clarity) dioptimalkan \\
3 & Beri label pada buttons \\
\hline
\end{tabular}

Kemudian kritik dan saran yang diperoleh dari ahli materi adalah sebagai berikut. 
Tabel 4. Kritik dan Saran dari Ahli Materi

\begin{tabular}{cl}
\hline No. & \multicolumn{1}{c}{ Kritik dan Saran } \\
\hline 1 & $\begin{array}{l}\text { Contoh soal sebaiknya dibuat dengan lebih lengkap misalnya pada perusahaan dagang (mencari } \\
\text { pembelian bersih, tidak ada potongan pembelian) dan laporan arus kas penjelasannya terlalu singkat. }\end{array}$ \\
2 & Sebaiknya ada latihan soal praktek.
\end{tabular}

Selain kritik dan saran dari para ahli tersebut juga diperoleh data dari uji coba pengguna siswa sebagai berikut.

\section{Tabel 5. Kritik dan Saran dari Uji Coba Pengguna Siswa}

\begin{tabular}{cl}
\hline No. & \multicolumn{1}{c}{ Kritik dan Saran } \\
\hline 1 & Soal di cek kemampuanmu terlalu mudah \\
2 & Durasi video terlalu lama \\
\hline
\end{tabular}

\section{Pembahasan}

Penyajian data kuantitatif hasil penelitian dan pengembangan oleh validator ahli media, validator ahli materi, dan uji coba pengguna siswa adalah sebagai berikut:

Tabel 6. Analisis Validasi Ahli Media

\begin{tabular}{clcc}
\hline Nomor & \multicolumn{1}{c}{ Aspek yang dinilai } & Persentase $(\%)$ & Kriteria Kevalidan \\
\hline 1 & Bahan penarik perhatian & 92,86 & Valid/dapat digunakan \\
\hline 2 & Balikan (feedback) & 80 & Valid/dapat digunakan \\
\hline 3 & Keinteraktifan & 91,67 & Valid/dapat digunakan \\
\hline 4 & Soal latihan & 100 & Valid/dapat digunakan \\
\hline 5 & Lain-lain & 87,5 & Valid/dapat digunakan \\
\hline & Rata-Rata & $\mathbf{8 9 , 2 8}$ & Valid/dapat digunakan \\
\hline
\end{tabular}

Berdasarkan hasil analisis data validasi ahli media diperoleh nilai rata-rata sebesar $89,28 \%$ sehingga dapat disimpulkan bahwa media pembelajaran akuntansi menggunakan lectora inspire dikategorikan valid/dapat digunakan sebagai media pembelajaran bagi siswa selama proses belajar dinilai dari sudut pandang kualitas media.

Tabel 7. Analisis Validasi Ahli Materi

\begin{tabular}{clcc}
\hline Nomor & \multicolumn{1}{c}{ Aspek yang dinilai } & Persentase (\%) & Kriteria Kevalidan \\
\hline 1 & Penyajian materi & 80,77 & Valid/dapat digunakan \\
\hline 2 & Balikan (feedback) & 81,25 & Valid/dapat digunakan \\
\hline 3 & Kualitas Instruksional & 81,25 & Valid/dapat digunakan \\
\hline 4 & Soal latihan & 78,57 & Cukup Valid/dapat digunakan \\
\hline 5 & Lain-lain & 81,25 & Valid/dapat digunakan \\
\hline & Rata-Rata & $\mathbf{8 0 , 4 6}$ & Valid/dapat digunakan \\
\hline
\end{tabular}

Berdasarkan hasil analisis data validasi ahli materi diperoleh rata-rata sebesar $80,46 \%$ sehingga dapat disimpulkan bahwa media pembelajaran akuntansi menggunakan lectora inspire dikategorikan valid/dapat digunakan sebagai media pembelajaran yang akan menunjang kegiatan belajar mengajar bagi siswa dan guru yang dinilai dari aspek penyajian materi oleh ahli materi. 
Selanjutnya sebuah media pembelajaran hasil pengembangan yang telah dinilai oleh ahli media dan ahli materi belum dapat dikatakan valid secara keseluruhan, jika tidak diketahui mengenai respon maupun pendapat serta penilaian oleh pengguna dalam hal ini adalah siswa dikarenakan siswa yang nantinya akan mengoperasikan dan menggunakan media pembelajaran yang telah dikembangkan sehingga penilaian dari siswa adalah aspek penting untuk mengetahui kelayakan media pembelajaran yang telah dikembangkan.

Berikut ini disajikan hasil analisis validasi uji coba pengguna siswa melalui instrument angket tertutup.

Tabel 8. Analisis Validasi Uji Coba Pengguna Siswa

\begin{tabular}{clcc}
\hline Nomor & \multicolumn{1}{c}{ Aspek yang dinilai } & Persentase $(\%)$ & Kriteria Kevalidan \\
\hline 1 & Bahan penarik perhatian & 97,16 & Valid/Dapat digunakan \\
\hline 2 & Penyajian materi & 96,32 & Valid/Dapat digunakan \\
\hline 3 & Balikan $($ feedback $)$ & 95,77 & Valid/Dapat digunakan \\
\hline 4 & Keinteraktifan & 92,02 & Valid/Dapat digunakan \\
\hline 5 & Kualitas instruksional & 98,53 & Valid/Dapat digunakan \\
\hline 6 & Latihan soal & 96,08 & Valid/Dapat digunakan \\
\hline 7 & Lain-lain & 96,32 & Valid/Dapat digunakan \\
\hline & Rata-Rata & $\mathbf{9 6 , 3 0}$ & Valid/Dapat digunakan \\
\hline
\end{tabular}

Berdasarkan hasil analisis data validasi uji coba pengguna siswa diperoleh rata-rata sebesar 96,30\% sehingga dapat disimpulkan bahwa media pembelajaran akuntansi menggunakan lectora inspire dikategorikan valid/dapat digunakan sebagai media pembelajaran yang akan memudahkan siswa dalam mempelajari materi laporan keuangan perusahaan jasa dan dagang sehingga dapat meningkatkan hasil belajar.

\section{Perbedaan Hasil Belajar Siswa Kelas X Akuntansi di SMK Negeri 1 Malang dengan} Media Pembelajaran Akuntansi Menggunakan Lectora Inspire

Perbedaan hasil belajar siswa setelah menggunakan media pembelajaran akuntansi lectora inspire diketahui dengan cara membandingkan hasil belajar antara kelas kontrol dan kelas eksperimen. Hasil belajar dalam penelitian ini diperoleh dari nilai pretest-posttest yang diukur dari nilai gain score. Uji yang digunakan adalah independent sample t-test dengan hasil bahwa nilai Sig. (2-tailed) sebesar 0,0150<0,05. Berdasarkan hal tersebut maka dapat dinyatakan bahwa terdapat perbedaan hasil belajar siswa kelas eksperimen dan kelas kontrol. Kesimpulan yang dapat diambil adalah terdapat perbedaan hasil belajar siswa yang lebih baik dengan menggunakan media pembelajaran akuntansi lectora inspire pada kelas X Akuntansi di SMK Negeri 1 Malang. 


\section{SIMPULAN DAN SARAN}

\section{Simpulan}

Media pembelajaran akuntansi menggunakan lectora inspire pada pokok bahasan laporan keuangan kelas X Akuntansi ini dikembangkan menggunakan model pengembangan yang beracuan pada Borg and Gall (1983) yang dimodifikasikan dengan Sadiman (2010) sehingga terdiri dari 9 langkah yaitu penelitian dan pengumpulan data, perencanaan, validasi ahli, pengembangan draft produk, produksi media, revisi produk, uji coba lapangan, revisi produk hasil uji coba lapangan, dan produk akhir.

Media pembelajaran akuntansi menggunakan lectora inspire tergolong multimedia interaktif tingkat operator dimana pengguna dapat mengoperasikan sesuai dengan keinginan dan kebutuhannya. Selain itu media pembelajaran dapat digunakan secara mandiri maupun klasikal yaitu dengan bantuan arahan dari guru sesuai dengan model pembelajaran yang digunakan guru dalam kegiatan belajar mengajar. Meskipun demikian, disarankan agar pembelajaran dilakukan dengan arahan guru sebagai fasilitator dan mediator sehingga hasil belajar siswa dapat lebih maksimal.

Dalam penelitian ini, prosedur pengembangan bukan hanya diarahkan pada uji kelayakan produk namun dilakukan uji keampuhan produk melalui eksperimen. Berdasarkan hasil eksperimen diketahui bahwa kelas eksperimen yang merupakan kelas dengan perlakuan pemberian pengajaran dengan media pembelajaran menggunakan lectora inspire diperoleh hasil belajar yang lebih baik dibandingkan dengan kelas tanpa perlakuan.

\section{Saran}

Berdasarkan hasil pengembangan yang dihasilkan, terdapat beberapa saran yang diberikan antara lain sebagai berikut:

1. Untuk guru

Pembelajaran dikelas dengan menggunakan lectora inspire akan lebih baik jika dengan bimbingan guru meskipun siswa dapat belajar secara mandiri. Hal tersebut dikarenakan siswa masih memerlukan penjelasan dari guru agar tidak terjadi kesalahan dalam pemahaman siswa jika hanya atas konstruksi siswa sendiri.

2. Untuk siswa

Siswa dapat mengoperasikan sendiri media pembelajaran menggunakan laptop yang sebagian besar dimiliki siswa diluar jam pelajaran untuk memperdalam pemahaman siswa terhadap penjelasan yang telah diberikan guru dikelas. 
3. Untuk peneliti selanjutnya

Saran untuk pengembangan bagi peneliti selanjutnya adalah:

a) Produk yang dihasilkan peneliti masih belum bermuatan IFRS namun sudah sesuai dengan silabus. Alangkah lebih baik jika produk yang dikembangkan selanjutnya adalah materi akuntansi yang bermuatan IFRS dikarenakan materi tersebut dapat menambah pengetahuan siswa lebih mendalam lagi mengenai akuntansi.

b) Belum terdapat buku panduan (tutorial) mengenai tata cara pembuatan (produksi) media untuk guru. Sehingga akan lebih baik jika dikembangkan buku panduan tersebut untuk memudahkan guru menyusun media pembelajaran sendiri dengan software media yang serupa dan disesuaikan dengan kebutuhan pembelajaran.

\section{DAFTAR RUJUKAN}

Arsyad, A. (2013). Media Pembelajaran. Jakarta: PT RajaGrafindo Persada. Budiningsih, A. (2004). Belajar dan Pembelajaran. Yogyakarta: PT Rineka Cipta.

Borg, W.R. \& Gall, M. D. G. (1983). Educational Research: An Introduction. New York: Longman.

Sadiman, A. S., dkk. (2010). Media Pendidikan. Jakarta: PT Raja Grafindo Persada.

Sudjana, N. \& Rivai, A. (2011). Media Pengajaran. Bandung: Sinar Baru Algesindo. 